\title{
Sentidos del trabajo en el capitalismo de plataformas: Análisis de narrativas audiovisuales en la gig economy
} The meaning of work in platform capitalism: An analysis of audiovisual ads from the gig economy

\author{
Magdalena Garcés Ojeda \\ Pamela Frías Castro \\ Antonio Stecher \\ Universidad Diego Portales
}

\begin{abstract}
Resumen
La expansión del capitalismo de plataformas o de la gig economy es una característica del mundo del trabajo contemporáneo. Junto al despliegue de nuevas formas de vinculación laboral y organización del trabajo, que han supuesto procesos de precarización, individualización y fragmentación de las experiencias laborales, es posible observar una activa producción de discursos que buscan legitimar el modelo de negocio de las empresas de plataformas. Se presentan resultados de un estudio cualitativo exploratorio que analizó desde un enfoque narrativo tres producciones audiovisuales publicitarias de dichas empresas, analizando los sentidos que construyen respecto al trabajador, la actividad de trabajar y la empresa. Constatamos que dichas producciones se orientan a legitimar estas formas de trabajo a partir de la apelación a sentidos de autonomía, flexibilidad, dinamismo, alto desempeño y utilidad social, que invisibilizan y naturalizan los mecanismos de precarización y dominación social que juegan un rol central en el capitalismo de plataformas.
\end{abstract}

Palabras clave: Capitalismo; Economía a demanda; Sentidos del trabajo; Recursos audiovisuales

\begin{abstract}
The growth of platform capitalism or gig economy is pervasive in today's labour market. Alongside with a new organization of work and novel labour bonds, which have fragmented and turned workers' experience into precarious work, it is possible to find a prolific production of discourses which aim at legitimizing the business model of the gig economy. Based on an exploratory qualitative research and narrative approach, this paper analyzes three audiovisual ads in their power to shape meaning making around workers' sense of selves, their tasks and the companies they work for. Our findings suggest that these audiovisual productions appeal to positive job traits such as autonomy, flexibility, dynamism, high achievement and social benefits, in an attempt to naturalize, legitimize and obscure power and precarity dynamics that play a key role in platform capitalism.
\end{abstract}

Keywords: Platform Capitalism; Gig economy; Meaning of work; Audiovisual narratives 


\section{INTRODUCCIÓN}

Un rasgo característico del mundo del trabajo contemporáneo, tanto en los países centrales como en el sur global, es la creciente expansión de actividades laborales vinculadas a lo que se ha denominado como gig economy, "economía bajo demanda" o "economía de trabajo temporal". Estas distintas denominaciones buscan dar cuenta de aquellos modelos de negocio basados en plataformas digitales que -a partir de su capacidad de registrar, almacenar y gestionar digitalmente y en tiempo real grandes cantidades de datos- vinculan las demandas de consumidores por ciertos servicios o productos, con la oferta de trabajo por parte de individuos disponibles para dar respuesta a dichas demandas (Kaine y Josserand, 2019; Srnicek, 2018). Un elemento clave de este modelo de negocio es el ocultamiento de la relación laboral que hacen las empresas de plataformas, presentándose como meras intermediarias tecnológicas entre las demandas de los consumidores y la oferta de fuerza de trabajo. Esto, considerando a los trabajadores/as como contratistas independientes, respecto de los cuales las empresas no tendrían ninguna obligación de protección laboral (Antunes y Filgueiras, 2020; Kaine y Josserand, 2019). Dentro del amplio territorio de la gig economy la literatura distingue tanto trabajos que implican una transacción local (tales como entrega de comida, mensajería y transporte) y que por tanto requieren la presencia física del trabajador; como aquellos que se realizan de forma remota a través de plataformas $w e b$, y donde se encuentran una amplia variedad de servicios digitales que van desde el ingreso de datos hasta la programación de softwares (Gleim, et al., 2019; Kaine y Josserand, 2019; Smith y Leberstein, 2015; Wood et al., 2019).

De acuerdo con Nick Srnicek (2018), las plataformas digitales -sobre las que se sostiene la gig economy - pueden ser entendidas como un nuevo tipo de empresa capitalista, orientadas por el imperativo de la rentabilidad, la reducción de costos y la constante optimización de la productividad a través de innovaciones tecnológicas y organizativas. Estas empresas se caracterizan por su capacidad de extraer, controlar y gestionar datos; por operar como una infraestructura digital que vincula diferentes actores (consumidores y trabajadores); por dinámicas monopólicas generadas por los efectos de ampliación permanente del volumen de datos y del tamaño de la red; y por generar distintas formas de subordinación y control sobre los trabajadores a través de las mismas plataformas y sus aplicativos. Esto último, al mismo tiempo que se les niega su estatus de empleados dependientes, considerándolos, para reducir costos laborales, como contratistas independientes sobre los cuales las empresas no tendrían ninguna responsabilidad (Antunes y Filgueiras, 2020; Ugarte, 2020). 
La consolidación del capitalismo de plataformas en la última década ha generado nuevas formas digitalmente mediadas de organización del proceso de trabajo, y ha contribuido a acelerar tendencias previas de pérdidas de derechos y precarización del empleo inherentes al capitalismo flexible y al modelo neoliberal (Goods et al., 2019; Muntaner, 2018; Srnicek, 2018). Esto ha dado lugar a una gran cantidad de debates en la esfera pública y académica respecto al futuro del trabajo, las leyes laborales y el impacto de las tecnologías en la calidad del empleo (Kaine y Josserand, 2019). Esta discusión ha cobrado creciente relevancia en el actual contexto de Pandemia por COVID-19, dado el aumento explosivo de este tipo de actividad en el marco de las medidas de confinamiento a nivel mundial, que aceleraron la transformación digital y llevaron a considerar a algunos de los trabajadores de plataforma (repartidores) como trabajadores esenciales. Asimismo, la crisis económica y el desempleo sin precedentes generados por la pandemia ha convertido este tipo de actividad en la única y principal fuente de ingresos de miles de personas a lo largo del mundo (OIT, 2021).

Existe una amplia producción académica que ha investigado el impacto de la gig economy a nivel de las legislaciones laborales (Hagiu y Wright, 2019; Smith y Leberstein, 2015); las experiencias cotidianas de trabajo (Gleim et al., 2019; Kaine y Josserand, 2019; Vaclavik y Pithan, 2018); el lugar que las tecnologías ocupan en términos de las transformaciones del trabajo, las modalidades de control y los modelos empresariales (Howcroft y Bergvall-Kåreborn, 2019; Srnicek, 2018; Vallas, 2019; Veen et al., 2019); los perfiles sociodemográficos de la fuerza de trabajo (López de la Fuente, 2019; MacDonald y Giazitzoglu, 2019); la calidad de vida y riesgos laborales (Goods et al., 2019; Wayne, 2017); así como su impacto en términos del acentuamiento de las relaciones de dominación capital-trabajo (Fleming, 2017; Ivanova et al., 2018; Muntaner, 2018; Shibata, 2019).

Sin embargo, la revisión de la literatura especializada da cuenta de una menor investigación sobre las producciones simbólicas o discursos a partir de las cuales las empresas de la gig economy buscan naturalizar y legitimar su modelo de negocio, basado en el uso de plataformas digitales y en el no reconocimiento de la relación laboral. Como han señalado Luc Boltansky y Eve Chiapello (2002) el capitalismo -entre ellos el de plataforma- necesita producir marcos interpretativos orientados a dotar de legitimidad, ante los ojos de la sociedad y los mismos trabajadores, los modelos de negocio y acción empresarial que en un determinado momento histórico organizan, de una particular manera, la explotación del trabajo por parte del capital. 
El presente artículo busca contribuir a abordar esa brecha de conocimiento presentando los resultados de un estudio exploratorio de carácter cualitativo cuyo objetivo fue analizar las narrativas audiovisuales de la publicidad de tres empresas de la gig economy en América Latina. A partir del análisis de la publicidad de tres compañías que ofrecen el servicio de reparto a domicilio en Argentina, México y Perú, el artículo busca destacar, describir y comprender el modo en que la expansión de la gig economy ha implicado la puesta en circulación de nuevos y particulares sentidos respecto a (i) lo que es ser un trabajador, (ii) la actividad de trabajar y (iii) el valor y lugar en la vida social de las empresas de plataformas. Desde una perspectiva crítico-interpretativa de investigación social (Thompson, 2004), el artículo describe y analiza dichos sentidos sobre el trabajo presentes en la publicidad de las tres empresas, discutiendo el modo en que los mismos buscan legitimar y dotar de valor social y subjetivo las formas de trabajo características del capitalismo de plataformas. Legitimación que supone naturalizar como algo inevitable, virtuoso y moderno estos nuevos modelos de negocio y trabajo basados en plataformas, así como invisibilizar la relación de dominación social sobre la que estos se han constituido (Antunes y Filgueiras, 2020).

\section{CARACTERÍSTICAS DEL TRABAJO EN LA GIG ECONOMY}

Las empresas de plataforma suponen un nuevo modelo de actividad económica y de trabajo caracterizado por el uso de tecnologías de nube (cloud-based technologies) como plataformas online o aplicativos para Smartphone. Estos soportes tecnológicos operan como interfaces digitales que conectan trabajadores, que ofrecen realizar servicios o tareas, con personas o organizaciones que requieren un particular servicio o producto (Vallas, 2019; Kaine y Josserand, 2019). Se trata de un modelo triangular (trabajador, cliente y empresa de plataforma) en que los trabajadores son considerados contratistas independientes y no cuentan con protecciones laborales, y donde la infraestructura digital otorga a las empresas un alto poder para organizar el proceso de trabajo y controlar a los trabajadores a través de distintos algoritmos y la gestión masiva de datos (Gandini, 2018, Kaine y Josserand, 2019).

El trabajo en plataformas puede clasificarse en cuatro tipos considerando los criterios de presencialidad del trabajo y nivel de complejidad de tareas y habilidades requeridas (Vallas, 2019). Por un lado, están los trabajos que se realizan de forma remota a través de plataformas (crowdwork), los que pueden ir desde labores de tipo repetitivas, y fragmentadas, como el llenado de encuestas (Ej. Amazon Turk), hasta aquellas que requieren una mayor cualificación como tareas diseño gráfico, programación, etc. Por otro lado, están aquellas 
actividades que requieren la presencialidad del trabajador. En este ámbito podemos encontrar trabajos de mayor complejidad y cualificación, como lo son los servicios de cuidado a domicilio o reparación en el hogar. A su vez, dentro de los trabajos mediados por plataforma que requieren presencialidad, están aquellos que suponen un menor grado de calificación y complejidad, tales como las labores de traslado que realizan conductores (Ej. Uber) o el trabajo de repartidores (delivery) de comida o productos (Ej. Ubereats, Pedidos Ya).

Centrándose en el trabajo de los repartidores de empresas de plataforma, que constituye el foco del análisis de este artículo, es posible señalar que este posee las siguientes tres características, las que son extensibles e ilustran en términos más transversales la gig economy.

En primer lugar, la expansión de la lógica del sistema "justo a tiempo" -propia de la industria manufacturera- al ámbito de servicios (Vallas, 2019). En este tipo de ocupación las personas ya no son contratadas para desempeñar un rol y un trabajo, sino que más bien se las vincula sólo para realizar tareas puntuales según la demanda que activan los clientes, en segmentos de tiempo discontinuos, donde no existen límites que determinen pausas ni descansos (Vallas, 2019). Esta lógica se asocia también a la realización de tareas altamente estandarizadas, fragmentadas y homogéneas, que han incidido en la descualificación del trabajo, disminución de posibilidades de desarrollo de habilidades y precarización del empleo (Goods et al., 2019; Ivanova et al., 2018; Kaine y Josserand, 2019; MacDonald y Giazitzoglu, 2019; Shibata, 2019; Wood et al., 2019).

En segundo lugar, este tipo de trabajo se caracteriza por el control y la gestión algorítmica del proceso de trabajo, a partir de lo cual se dirige, monitorea, evalúa y disciplina a los trabajadores. Se trata de un sistema de control, fijación de tarifas y asignación de tareas; así como de trazabilidad de horarios, desplazamientos y tareas realizadas, a partir de los datos que registran en tiempo real los aplicativos. Asimismo, la gestión algorítmica se basa fuertemente en sistemas de calificación y reputación a partir de evaluaciones cuantitativas que las y los clientes deben completar después de la entrega (Vallas, 2019; Wood et al., 2019). El control algorítmico impacta en forma negativa en las condiciones de trabajo y calidad de vida laboral, pues se asocia a altos niveles de intensificación del trabajo, el monitoreo y evaluación constante desde los aplicativos, la disminución de pausas y tiempos de descanso, el cambio unilateral de las tarifas y pagos, y las extensas jornadas laborales para alcanzar los ingresos esperados (Goods et al., 2019; Lewchuk, 2017).

En tercer lugar, este tipo de trabajo se caracteriza por la redefinición legal de las formas de relación laboral y estatuto del trabajo (Vallas, 2019): La econo- 
mía de plataformas progresivamente se ha ido consolidando como un mercado laboral caracterizado por la ausencia de una relación laboral contractual y el hecho de que quienes trabajan en este espacio, en general, no son considerados empleados/as de la empresa que representan, sino que son categorizados como "trabajadores independientes" o por "cuenta propia” (Gleim et al., 2019; Ivanova et al., 2018). Esta forma de relación laboral ha implicado el reemplazo de las tradicionales reglas administrativas y del derecho laboral, lo cual trae consigo la pérdida de protecciones, soportes y derechos sociales, con el desplazamiento de los riesgos económicos y la responsabilidad de equipamiento (celulares, motos, bicicletas) y desarrollo de habilidades hacia los trabajadores. Todo ello implica una fuerte precarización del trabajo, al mismo tiempo que reducción de costos y mayor rentabilidad para las empresas (Fleming, 2017; Wood et al., 2019). Asimismo, esta ausencia de relación laboral formal produce una fuerte individualización de las experiencias de trabajo y dificulta las posibilidades de organización y negociación colectiva de los trabajadores frente a las empresas.

Respecto de la fuerza de trabajo es difícil estimar el número exacto de trabajadores en la gig economy, dado que las empresas suelen ser reacias a revelar este tipo de información, o bien, cuando existen cifras disponibles, no es fácil hacer una estimación confiable, puesto que, por ejemplo, los trabajadores/as pueden estar registrados para varias compañías al mismo tiempo (De Stefano, 2016). De acuerdo con un estudio realizado por Lawrence Katz y Alan Krueger (2019) en el 2015 un 0,5\% de la fuerza de trabajo de la economía de Estados Unidos correspondía a personas que brindan servicios a través de "supuestos intermediarios" en línea, como Uber o TaskRabbit. Sin embargo, la actual situación sanitaria ha cambiado esta situación. Según la OIT (2021), el trabajo en plataformas ha tenido un explosivo aumento en esta pandemia, especialmente en países con altos niveles de desempleo e informalidad laboral, donde esta alternativa puede representar la única fuente de ingresos para miles de personas, en especial migrantes, quienes se dedican en forma intensiva y exclusiva al trabajo en plataformas (CEPAL OIT, 2020).

En el caso de América Latina, los últimos datos de la OIT señalan que la mayoría de los trabajadores de plataforma son menores de 35 años, con alto nivel de estudio y con un predominio de trabajadores hombres, que representan, para el caso de las plataformas que requieren trabajo presencial (reparto o conducción), alrededor de un $90 \%$ de la fuerza de trabajo (OIT, 2021). A diferencia de otros continentes, en América Latina este tipo de trabajo puede representar un ingreso mayor al sueldo mínimo y al de otro tipo de ocupación de baja calificación (Berg et al., 2019). El promedio de edad de quiénes trabajan en América 
Latina sería de 28 años, cifra menor al promedio de países desarrollados (Madariaga et al., 2019).

Por último, es importante consignar que los estudios sobre las empresas de plataformas y la gig economy dan cuenta de su estrecha conexión con el imaginario neoliberal (Laval y Dardot, 2013) y la apelación a ideales de sujeto basados en atributos como la flexibilidad, dinamismo, independencia, emprendimiento y autorealización (Bröckling, 2015). En esta línea, los discursos utilizados por las empresas de plataformas para legitimarse ante la sociedad, así como para atraer a la fuerza de trabajo, especialmente a los más jóvenes, realza atributos como la posibilidad de "ser su propio jefe", tener autonomía para definir los propios horarios y generar ingresos de manera entretenida, ser parte de una actividad laboral "que más que un trabajo" es un desafío o juego continuo (work-games) (Manriquez, 2019). Así también, el discurso oficial sobre la gig economy realza su relevancia en términos de su aporte al crecimiento económico, la generación de nuevos empleos y la satisfacción de distintas necesidades de los usuarios (Shibata, 2019).

\section{METOdologíA}

Se desarrolló un estudio cualitativo de carácter exploratorio enmarcado en una perspectiva crítico-interpretativa de investigación social, siguiendo los aportes de la hermenéutica profunda (Thompson, 2002). Se analizaron las campañas publicitarias audiovisuales de tres empresas de plataformas de reparto en América Latina. En tanto construcciones simbólicas, las producciones audiovisuales constituyen un tipo de narrativa, en la que es posible encontrar mucho más que la suma de elementos visuales y auditivos (Rivera y Correa, 2006). Estas pueden revelar significados y sentidos singulares que buscan interpelar a los actores sociales, y dan cuenta de fenómenos culturales y formas simbólicas más amplias ancladas en los contextos sociohistóricos que las estructuran y condicionan (Thompson, 2002).

En las narrativas audiovisuales es posible distinguir una historia, compuesta de personajes, situaciones y acciones diversas anudados coherentemente en una trama que se despliega temporalmente (Riessman, 1993; Thompson, 2002). Dichas narrativas movilizan mandatos, modelos y significaciones que se ofrecen a los individuos para la interpretación de sus experiencias sociales, la orientación de sus interacciones con otros y la configuración de narrativas personales (Melucci, 2001). Las narrativas audiovisuales analizadas se ofrecen como modelos o narrativas canónicas que vehiculizan particulares ideales, modelos y sentidos del trabajo, ofreciendo matrices de inteligibilidad a partir de las cuales 
valorar y comprender de una particular manera las experiencias laborales en la gig economy (Portocarrero, 2001; Sisto y Fardella, 2009; Stecher, 2009, 2013).

\section{MUESTRA}

Para el propósito del estudio, se seleccionaron y analizaron las producciones audiovisuales publicitarias de tres empresas que corresponden a plataformas de servicios de reparto presentes en tres países latinoamericanos (Argentina, México y Perú). Dentro de los criterios de inclusión se consideró: a) que fuesen producciones audiovisuales de empresas de reparto con presencia en Latinoamérica, b) idioma español y, c) que en su contenido (trama, imágenes, mensajes) hicieran alusión a la experiencia de trabajo a través de la presencia de la figura del repartidor y su interacción con clientes.

\section{Análisis de datos}

Para el análisis de las producciones audiovisuales se establecieron tres etapas siguiendo los principios de la hermenéutica profunda (Ricouer, 2003; Thompson, 2004).

En un primer momento, se realizó una revisión teórica de literatura especializada sobre la gig economy, que permitió reconstruir los antecedentes y particulares condiciones sociohistóricas en las que ésta emerge y la particularidad de su lógica empresarial, modelo de negocio y proceso de trabajo. Lo anterior, poniendo un foco en el trabajo de reparto y en el desarrollo de las empresas de plataforma en América Latina.

En segundo lugar, cada uno de los/as investigadores realizó un análisis de orientación narrativa de las producciones audiovisuales (Thompson, 2002), poniendo especial atención al contenido, estructura y elementos visuales de la trama narrativa que presentaba cada publicidad, con una grilla predefinida, orientada a analizar los efectos de significación a nivel de la representación del trabajador, de la actividad de trabajar y de las empresas de plataformas. De este modo, y siguiendo los aportes de Bárbara Czarniawska (2004), el análisis se orientó por las siguientes tres preguntas: ¿Qué nos dice esta historia? (poniendo énfasis en el contenido y temas que emergen sobre los repartidores, el trabajo y la empresa); ¿Cómo se cuenta la historia a partir de la combinación de ciertas imágenes, sonidos y textos? (relevando elementos discursivos de las narrativas y su composición) y ¿Para qué se cuenta esta historia? (Profundizando en la dimensión performativa y función social de la narrativa audiovisual).

En tercer lugar, y más allá del nivel descriptivo, se triangularon los resultados del análisis realizado por cada investigador/a, con el fin de construir una sínte- 
sis o explicación interpretativa de los sentidos que en las narrativas se construyen respecto al trabajador, la actividad de trabajar y la empresas de plataforma, dando cuenta de la articulación entre las formas simbólicas analizadas (narrativas audiovisuales) y el contexto sociohistórico de surgimiento y desarrollo de la gig economy, entendida como una particular modalidad histórica de configuración de las relaciones sociales capital-trabajo.

\section{Descripción de los videos}

Antes de presentar los resultados del análisis y discusión describiremos brevemente cada una de las producciones audiovisuales:

Uber Eats llega a Lima (Uber Eats, 2018)

Esta producción audiovisual anuncia la llegada de esta marca a la capital peruana. El anuncio filmado en un sector acomodado de la ciudad (Miraflores), muestra a un reconocido jugador de la selección de fútbol, Aldo Corzo, en una bicicleta, vestido de manera casual, cargando la mochila de reparto que caracteriza esta labor. En la primera escena, se muestra a un niño que se le cae un helado. Su madre mira el teléfono móvil en busca de una solución e inmediatamente aparece este repartidor con un nuevo helado. En una segunda escena, se aprecia al repartidor pedaleando en la ciudad, recibiendo saludos de quienes lo reconocen y saludan. En su trayecto, éste se da el tiempo para hacer algunos pases en un partido de barrio mientras entrega una pizza. Luego, sigue su camino en busca del tercer y último pedido. La pieza audiovisual, cuya duración es menor a un minuto, termina con la entrega de un pedido en la casa del mismo niño del inicio, quién abraza al futbolista que se despide afectuosamente y luego sigue su camino. Cada escena, se acompaña de un mensaje gráfico que señala las principales características del servicio: alcance ("Más de 300 restaurantes disponibles"), disponibilidad ("En cualquier momento del día”), objetivos ("Encuentra tu comida favorita"), facilidades ("Recíbelo donde estés") y rapidez ( "Ordena en un solo toque"). La interacción verbal entre repartidor y clientes está ausente. La fotografía del video muestra espacios bien iluminados y sectores que pertenecen a espacios urbanos de clase media alta de la ciudad. La publicidad tiene una duración de 52 segundos. De fondo se puede oír la canción “Boom, boom, boom” de Cherry'z.

Pedidos Ya, Pide lo que quieras, que te lo llevamos volando (Pedidos Ya, 2019) Esta producción argentina comienza mostrando, de manera intercalada, imágenes de la plataforma y dispositivo en el que se está realizando un pedido. El repartidor -a quién no se le ve el rostro-, se está poniendo una chaqueta de cuero, sobre una polera roja con el logo de la Marca, unos guantes de ciclista y 
su mochila de reparto. En una siguiente escena, el repartidor aparece sobre la bicicleta con su mochila lista, para iniciar la compra y el reparto de los productos solicitados. Para realizar el delivery, éste debe sortear distintos obstáculos, lo que realiza con destreza (piruetas) y gran velocidad. Sin interacción verbal con los clientes y siempre sobre su bicicleta, el repartidor logra entregar en tiempo y forma los diversos pedidos -café con borra de cara sonriente, pañales, alimento para mascotas, pizza, preservativos y hielo- que se realizaron a través de la plataforma durante día y noche. Las escenas transcurren en lo que parece ser la capital de este país, por la presencia de grandes edificios y estaciones del metro subterráneo. La producción audiovisual tiene una duración menor a un minuto de tiempo. De fondo se escucha una versión de "Run way or another" del grupo Blondie. La publicidad termina con la frase corporativa de "Pide lo que quieras y te lo llevamos volando".

\section{Sin Delantal, campaña "éntrale" (Sin delantal, $s / f$ )}

Esta producción mexicana muestra un repartidor que viste uniforme de color rojo. En cada una de sus entregas procede a leer en voz alta el detalle del pedido y luego interactúa verbalmente con los clientes. En la primera entrega (pizzas), lo reciben 3 hombres vestidos de mujer, que señalan haber perdido una apuesta y les tocó pagar. En la segunda entrega (hamburguesas con kétchup y papas con carita feliz), lo recibe una niña que rompe contra el suelo una alcancía con monedas -el pago por el servicio- que luego éste procede a recoger y contar antes de retirarse. En la tercera entrega (ostiones, fresas y espumante), le abre la puerta un hombre mayor, quien, al oír el llamado de una mujer, con quien pareciera tener una cita amorosa, le guiña el ojo al repartidor y le ofrece quedarse con el cambio. En la cuarta entrega (sopa de coditos con sazón de "mamá Lupita"), una mujer joven que se aprecia cansada en medio de lo que parece ser una mudanza, al verlo le dice que es su héroe, abrazándolo, señalando que extraña a su madre. En la quinta entrega (ensalada orgánica con frutos rojos y jugo de apio), un hombre de apariencia corpulenta, con tatuajes en la frente y algo intimidante lo recibe preguntando insistentemente si el pedido trae sus "tomatitos cherry". Frente a la respuesta afirmativa del repartidor, quien asegura que ésta los contiene en gran cantidad, éste se despide afectuosamente chocando sus puños. En la sexta y última entrega (tacos al pastor y dos litros de bebida), en una oficina, lo recibe un trabajador nuevo, quien choca con una mampara de vidrio, se lesiona y es auxiliado por el repartidor. Finalmente, la producción audiovisual termina con las imágenes de cada uno de los clientes disfrutando su pedido y una voz en off señala: "Tenemos diferentes tipos de comidas para diferentes tipos de antojos". 


\section{RESULTADOS: ANÁLISIS DE NARRATIVAS AUDIOVISUALES}

Se presentan los resultados del análisis de las narrativas de las producciones audiovisuales de las empresas de plataforma consideradas, los cuales se articularon en torno a tres categorías: 1) la figura del repartidor 2) el proceso de trabajo y la 3) la compañía u organización.

Es importante remarcar que el análisis da cuenta de los sentidos que emergen respecto a estos tres ejes en las producciones audiovisuales analizadas, no constituyendo en ningún caso una descripción del proceso de trabajo efectivo en las empresas, ni una reconstrucción de las experiencias laborales y sentidos subjetivos desde la perspectiva de los trabajadores de reparto. Su foco es justamente tratar de reconstruir el modo como las empresas de plataformas buscan configurar y difundir una particular interpretación de lo que es el trabajo de plataformas, de cara a legitimar su forma de operar ante la sociedad y los mismos trabajadores.

\section{La figura del repartidor: ¿Súper héroe, deportista o trabajador de reparto?}

Tanto en el caso de Uber Eats como en el de Pedidos Ya, el repartidor es presentado como un sujeto ágil, deportista y dinámico. Aldo Corzo se viste con ropa deportiva y en todo momento es mostrado en movimiento ya sea pedaleando o dominando el balón. En el caso de Pedidos Ya, el repartidor utiliza un casco y chaqueta de cuero, que lo hacen parecer un motociclista experto más que un repartidor. Este último, pedalea a gran velocidad, realizando saltos y piruetas que denotan una sorprendente destreza física y dominio de la bicicleta. Ambos repartidores se muestran enérgicos y activos, y su destreza causa admiración entre quiénes los ven pasar. Sólo la distintiva mochila cuadrada donde llevan los pedidos nos recuerda que quienes parecen ser deportistas exitosos y de alto rendimiento, están realizando labores de reparto.

Ambos personajes se muestran como personas capaces de responder a los requerimientos de los demás, con altos niveles de satisfacción y desempeño: los pedidos siempre llegan a tiempo y en el momento oportuno. El repartidor, que nunca se aprecia cansado o molesto, pareciera ser alguien cercano y empático, para quién responder a las necesidades de los demás, pareciera ser fuente de energía y satisfacción. Esto se aprecia en múltiples imágenes donde la satisfacción del cliente, demostrada en una permanente sonrisa, es la que pareciera impulsar la acción de seguir el camino hacia la entrega de un nuevo pedido. Emerge, así, la figura de un sujeto que es capaz de desempeñar su tarea de reparto conjugando un alto nivel, tanto de eficiencia y desempeño, como de satisfacción y goce, en un circuito en que ambos aspectos -el desempeño y la satisfacción- se potencian entre sí. 
En ambas producciones la música de fondo refuerza la imagen de vitalidad, dinamismo, intensidad y autodeterminación que se busca asociar al repartidor.

En la producción de Sin Delantal el repartidor, quién viste con una polera y gorro rojo, similares a las de un clásico repartidor de pizza, se muestra como una persona cercana y amable. Éste camina, sube escaleras y/o toca timbres con su mochila a cuestas, destacando su habitual sonrisa, que no desparece con el pasar de las horas y los clientes. Su actitud servicial se refuerza con una música ambiental de fondo, cuya melodía contempla el uso de algunos timbres que evocan el recuerdo de las campanillas con que se estila llamar al personal de servicio en algunos restaurantes, hoteles y/o mesones de atención. Frente a la expresión de afecto de los clientes, él responde de manera empática, adoptando una actitud de resguardo frente a la intimidad del cliente, quien, al momento de abrir la puerta de su casa, tiende a hacerlo partícipe de todo aquello que ahí sucede.

En estas tres producciones audiovisuales el repartidor pareciera ser una persona competente, ya sea por sus destrezas físicas y talento al conducir por la ciudad (como lo es en el caso de Uber Eats y Pedidos Ya), como por su capacidad de brindar un servicio que permite responder, justo a tiempo, a las necesidades de los demás, denotando dominio y capacidad de gestión de las propias emociones en favor de una respuesta acorde a las diversas situaciones que debe afrontar (Sin Delantal). Las narrativas audiovisuales movilizan, así, ciertos atributos de la figura del trabajador de reparto ligadas a la velocidad, responsabilidad y la actitud de servicio que exige un activo trabajo emocional. El repartidor siempre cumple a tiempo y en modo adecuado las diversas expectativas de los clientes. Su actitud de servicio se presenta como un interés o cualidad personal por realizar diversas labores que al mismo tiempo que ayudar a otros, causan satisfacción personal.

El repartidor, más que como trabajador, aparece significado como un individuo en movimiento en el espacio urbano, en interacción con la tecnología, con capacidad de reconocer y atender con velocidad y empatía las necesidades de otros. Este realiza una actividad que lo constituye como un sujeto activo, capaz, útil para los demás y reconocido por aquellos a quienes ayuda con algo que parece ser más que una simple entrega. En sintonía con esta representación del trabajador, la actividad de trabajar se caracteriza por ser intensa, activa y desafiante, similar a un hobby, deporte o juego. Aquello que la persona realiza depende en todo momento de sí mismo y de sus competencias. Esta actividad parece también sencilla y exenta de riesgos, en la medida que las destrezas y habilidades del repartidor -el hábil dominio de la bicicleta (Pedidos Ya), un destacado rendimiento como futbolista que le permite jugar en las 
grandes ligas (Uber Eats) y un elevado nivel de autocontrol, actitud servicial y paciencia (Sin Delantal) - parecen ser todo lo que se requiere para alcanzar sus objetivos.

A pesar de que los repartidores están solos y su actividad es siempre presentada como un desafío individual, las imágenes que muestran a clientes/proveedores y personas que los ven pasar sonriéndoles, operan como una recompensa y un modo de vinculación a otros. El repartidor sería alguien independiente, pero vinculado a otros y situado en un espacio urbano lleno de movimiento, conexiones y dinamismo. Alguien que desarrolla actividades desafiantes e intensas que le demandan, pero también lo llenan de energía. Esto se refuerza a través de imágenes que, por ejemplo, nos llevan a pensar en la adrenalina que siente el repartidor de Pedidos $\mathrm{Ya}$, o el disfrute que siente el repartidor de Sin Delantal frente a las diversas sorpresas que enfrenta tras cada apertura de puerta, lo que pareciera transformar el trabajo en una especie de aventura, prueba deportiva o desafío que se renueva en cada nuevo pedido. El trabajo como desafío o aventura transforman al repartidor en un agente alejado de las representaciones clásicas de un sujeto laboral. A su vez, el trabajo como juego constituiría una fuente de energía inagotable, pues los repartidores son presentados de día y de noche, en una actividad que parece sin fin, pero que sin embargo no parece mellar su energía. El repartidor no aparece nunca cansado, ni con necesidades básicas que atender (alimentarse, ir al baño, descansar), y no parece desear nunca el término de su actividad.

\section{El proceso de trabajo: “Jugando" a satisfacer justo a tiempo múltiples necesidades}

En concordancia con la representación del trabajador, la actividad misma de trabajar y el contenido del trabajo de reparto es presentada a partir de imágenes que evocan actividades deportivas, juegos o hobbies. Así como se desplaza la imagen del trabajador de reparto a la figura de un deportista (especialmente en Pedidos Ya y Uber Eats), de la misma manera la actividad de trabajar en sí y el proceso de trabajo implicado es resignificado en términos de un desafío deportivo individual. Las producciones audiovisuales tienden a mostrar el contenido del trabajo como tareas placenteras, energizantes y satisfactorias, como andar en bicicleta, jugar fútbol, reír con otros. A su vez, la ausencia en las imágenes de un pago o intercambio monetario en las entregas, de un jefe que da órdenes o de alguna interacción verbal con los clientes, refuerzan la idea de que la experiencia misma de reparto no es una actividad laboral y está desprovista de cualquier tensión o problema. Esto se aprecia principalmente en el caso de Pedidos Ya y Uber Eats. Sin embargo, igualmente en el video de Sin Delantal, el repartidor en su recorrido va conociendo diversas personas que viven 
situaciones difíciles (chocar con una ventana, exponerse al ridículo, estar enferma y sola en la ciudad) en las cuáles el repartidor interviene sin siquiera habérselo propuesto: su sola presencia pareciera ser gratificante para el cliente, quién incluso lo llama "héroe" en una ocasión.

La relación con las y los clientes se muestra amena y distendida. La amabilidad y el reconocimiento de éstos parecieran ser al mismo tiempo una fuente de gratificación y energía: tras realizar la entrega, el repartidor se muestra siempre enérgico y dispuesto. De este modo, la totalidad de sus interacciones serían positivas y carentes de tensión o conflicto. La actividad pareciera ser tan entretenida, motivadora y desafiante, que la posibilidad de experimentar agobio, tensión o estrés parecen lejanas o al menos ausentes en las narrativas audiovisuales. El repartidor pareciera contar con todo lo que se necesita para resolver las necesidades de los demás: su tiempo y energía son ilimitados, su disponibilidad es absoluta, cuenta con la capacidad física, ya sea para caminar por horas, pedalear o sortear los obstáculos más complejos para llegar "justo a tiempo".

Tanto en el video de Uber Eats, como en Pedidos Ya, la agilidad, rapidez y eficiencia se presentan como atributos clave de un buen servicio, que se entrega justo a tiempo, por lo que el repartidor se muestra constantemente en movimiento. En el caso de Sin Delantal, el proceso de trabajo y el uso del tiempo adquieren un carácter diferente. En este caso, el foco no está puesto en la rapidez de la entrega, sino más bien en aquello que implica el servicio: satisfacer una necesidad concreta, que constituye algo más que un producto: éste implica un servicio donde, como señala la frase publicitaria del final, permite satisfacer los más diversos "antojos". No obstante, en las tres producciones se refuerza la idea de la disponibilidad e inmediatez del trabajo que realizan los repartidores, quiénes constituirían emblemas de alto rendimiento: estos son capaces de enfrentar y resolver todo tipo de dificultad que se presente en su camino, no se toman pausas ni descansos y siempre aciertan en la entrega y resolución de problemas.

El trabajo, de esta manera, se presenta como una actividad constante, pero fragmentada en un continuo de entregas distintas, sin patrones temporales claramente delimitados y donde no parecen haber situaciones de tensión, conflicto o accidentes laborales. El repartidor pareciera estar disponible 24/7 para atender los requerimientos de los clientes, sin mayor necesidad de descanso, alimentación, apremio económico, etc. En las tres producciones, el repartidor se muestra indistintamente de día y de noche, siempre en movimiento. A su vez, no aparecen imágenes o alusiones a la dimensión colectiva del trabajo (apoyo, solidaridad, cooperación, intercambio). La actividad de trabajar es re- 
presentada como algo individual y las interacciones se producen con clientes y nunca con otros trabajadores/as. Al mismo tiempo, todo lo relativo a la evaluación, remuneración, control algorítmico y cualquier acción/interacción que refiera a la gestión del capital humano o procesos administrativos, propios de un empleo, se encuentran ausentes en los videos. La empresa aparece visualmente en las narrativas bajo el logo de las mochilas o bien, al final del material audiovisual. Al respecto, el análisis de la última escena del repartidor de Sin Delantal, en que de noche realiza la entrega en una oficina donde sólo queda el trabajador nuevo y aquel que hace aseo - situación que muestra un trabajo "clásico" de empleado de oficina solitario, encerrado, con vestimenta formal y pasivo- contrasta con la experiencia de múltiples interacciones y sociabilidad que aparece experimentado el repartidor en sus desplazamientos por la ciudad.

\section{La marca y su promesa: Aportamos al bienestar de nuestros clientes, "colaboradores" y de la sociedad}

Las tres producciones audiovisuales nos muestran compañías que enfatizan atributos de marca como la disponibilidad permanente, cercanía y alcance, que se concretan en la oferta de un servicio "todo terreno", "24/7" y "100\% satisfactorio", de gran valor para los clientes y el bienestar social. Esto se concreta en la idea de que el repartidor -cara visible de la empresa, aunque en algunas narrativas audiovisuales, sin rostro visible- entrega más que un simple producto: entrega alegría, consuelo, soluciones, paciencia, esperanza, etc.

Esto se aprecia en el caso de Pedidos Ya, donde la figura del repartidor encarna una especie de "héroe anónimo" al servicio de la comunidad, capaz de realizar arriesgadas maniobras en la bicicleta para abrirse camino y llegar a tiempo con las más diversas entregas. El repartidor en este caso literalmente "vuela" a gran velocidad, superando diversos obstáculos para llegar a tiempo con pañales que permitirán calmar a un bebé. Este le arregla el pelo desordenado al joven padre, quien se aprecia ojeroso tras lo que parece haber sido una muy mala noche dado que no tenían pañales. Este último gesto refuerza la idea de que, más que un producto, el repartidor ofrece su propia estabilidad, disponibilidad, empatía e incluso algo de su desbordante energía al cansado padre.

En el caso de Sin Delantal, la idea de accesibilidad, disponibilidad y servicio a toda prueba se refuerza en el logo de la marca: un chef a cuerda que camina cargando un plato de comida caliente, que en la animación final es empujado a través de lo que pareciera ser una especie de elástico que simula una catapulta. Imagen que transmite no sólo el alcance y facilidad de la marca para enviar todo tipo de alimentos a quiénes tienen antojos, sino que también nos permite pensar en el arrojo y disposición de sus serviciales "colaboradores". 
Las empresas se presentan también, implícitamente, como organizaciones que brindan oportunidades a los repartidores. Estos encontrarían en dichas plataformas la posibilidad de desarrollar una actividad entretenida, intensa, desafiante, que les permitiría ayudar a otros y (si bien este punto no aparece explícitamente) generar un ingreso para ellos. En los videos, por el contrario, no aparece nada que signifique a la empresa como un empleador, ni como un agente que controla y regula el proceso de trabajo, ni como un actor interesado en disciplinar y extraer producción y ganancia de sus trabajadores.

La empresa aparece de una forma difusa y etérea, como un agente que posibilitaría y activaría digitalmente la conexión y un vínculo colaborativo entre repartidores y clientes. Los repartidores no estarían al servicio de los clientes de manera servil, sino que, más bien, ellos se retroalimentarían positivamente y gozarían de este vínculo y reconocimiento. Esto se aprecia en múltiples tomas donde el repartidor se enfoca hacia lo alto, como alguien que está por sobre esa relación con el cliente. Por ejemplo, en Pedidos Ya, el motorista literalmente "vuela" con su moto por encima de la gente. Las imágenes y mensajes gráficos invitan - a clientes y repartidores- a vivir una experiencia donde la conectividad, diversidad, el fácil acceso y la posibilidad de satisfacer los propios gustos y necesidades resultan fáciles de concretar con un solo click. Las empresas brindarían así la posibilidad de una conexión horizontal a repartidores y clientes, permitiendo a los clientes satisfacer necesidades en forma rápida, y a los repartidores hacer una actividad entretenida y desafiante que les abre posibilidades de desarrollo y reconocimiento a partir de su propio esfuerzo y mérito individual.

En este sentido, las producciones audiovisuales refuerzan la idea de que el repartidor accedería, más que a un empleo a cambio de una remuneración, a la posibilidad de moverse en distintos espacios de la ciudad, a asumir tareas desafiantes, desarrollar destrezas físicas, y ser reconocido por su utilidad social. La invisibilización del rol de empleador de la empresa, es la contracara de la invisibilización del repartidor como empleado subordinado a distintas formas de control y disciplinamiento. La empresa y sus trabajadores aparecen en las narrativas como ajenas a cualquier forma tradicional de control como el "marcado de tarjeta" y la supervisión directa a través de una jefatura; así como distantes de labores rutinarias, falta de reconocimiento, aislamiento, etc. Al respecto, el nombre de la compañía Sin Delantal, nos evoca la idea de que aun cuando este es un trabajo de servicio, no implicaría el uso de un uniforme que identifique al individuo en ese rol, aún cuando en el video, contradictoriamente, éste es el único que lleva ropa de trabajo. 
En síntesis, las empresas se presentan no como compañías privadas orientadas por criterios de rentabilidad, sino como organismos orientados al bienestar de los demás. Por un lado, serían empresas que ofrecen a los clientes la posibilidad de atender y responder cualquier requerimiento, en cualquier momento, de una forma oportuna y a través de colaboradores empáticos, cordiales y comprometidos. Por otro lado, serían empresas que brindarían a los repartidores - por lo general, hombres y jóvenes- la posibilidad de una actividad dinámica, entretenida, al aire libre, basada en el uso de la tecnología, flexible, sin jerarquías ni disciplinas, en relación siempre con otras personas desde las cuales se obtiene reconocimiento, y las que permiten también una experiencia de utilidad social y bienestar personal.

\section{DISCUSIÓN}

A la luz del análisis, es posible plantear que, en las narrativas audiovisuales, el trabajo en la gig economy es narrado a través de un discurso de dinamismo, desafíos, disfrute, individualización, energía y plena disponibilidad. Un discurso donde todas las dimensiones de necesidad, subordinación, control y disciplina, propias de la relación laboral capitalista, quedan invisibilizadas.

Las frases y logos publicitarios, como así también las acciones e interacciones de los repartidores en los videos, sitúan a las empresas de plataformas como proveedores de un servicio que aporta al bienestar social, entendido en forma muy acotada en términos de la satisfacción de necesidades y "antojos" de los clientes, vistos como consumidores individuales orientados por sus deseos y necesidades.

A partir de la apelación a metáforas deportivas, el trabajo es presentado como una actividad demandante en términos de esfuerzo físico, pero satisfactoria y placentera. Las personas parecieran sentirse $100 \%$ satisfechas, retribuidas y reconocidas en su labor por los otros. El reparto se representa por parte de las empresas como una actividad libre y voluntaria que, tal como señalan Mark Gleim et. al (2019), implicaría renunciar a la estabilidad, a cambio de quedar liberados de ciertas "reglas" propias del trabajo convencional y acceder a mayores niveles de autonomía. De este modo, pareciera ser que ni los beneficios sociales, ni la retribución económica son lo fundamental, en la medida que la persona pareciera sentirse gratificada por el simple hecho de disfrutar haciendo algo que le gusta. El trabajo en las plataformas aparece también -junto a la idea de libertad y utilidad social - como una alternativa cercana y disponible de inserción laboral, asequible a quien lo desee y que ofrece posibilidades de desarrollo y puesta en juego de ciertas habilidades y destrezas. 
Los sentidos del trabajo descritos dan cuenta de un activo esfuerzo de invisibilización de todas aquellas dinámicas negativas y de dominación social asociadas a la gig economy, descritas en los antecedentes del artículo. Las narrativas construyen una imagen idealizada del trabajador, el trabajo y las empresas que oculta y/o naturaliza, como una realidad dada e inmodificable, aspectos tales como la responsabilización individual, la transferencia de riesgos a los trabajadores, la ausencia de protecciones y seguridad social, la intensificación del trabajo y el no pago de los tiempos muertos -en que se debe estar disponible,así como el control algorítmico que disciplina e intensifica el trabajo (Fleming, 2017). A través de la movilización de dichos sentidos -que resuenan y se potencian con los marcos culturales fuertemente individualizados de la matriz neoliberal contemporánea- las narrativas audiovisuales analizadas procuran contribuir a la legitimación social del capitalismo de plataformas de cara a la sociedad, los consumidores y los trabajadores, invisibilizando dinámicas de dominación social y precarización laboral ampliamente descritas para la gig economy (Antunes y Filguieras, 2020).

El análisis presentado constituye un ejercicio exploratorio que busca ser un aporte al esfuerzo de la Psicología Social del trabajo por comprender críticamente las transformaciones laborales contemporáneas, considerando sus dimensiones simbólicas y subjetivas. Por cierto, el análisis realizado no permite responder a la pregunta por los procesos efectivos de subjetivación laboral de los trabajadores de dichas compañías, por el modo en que los sentidos del trabajo movilizados por las empresas son (o no) apropiados y utilizados por los propios trabajadores para interpretar sus experiencias laborales, ni por el modo en que dichos sentidos se articulan con otros discursos sociales o narrativas disponibles presentes en la cultura. El artículo espera ser una contribución al desarrollo de dicha agenda de investigación psicosocial sobre el capitalismo de plataformas, la que debiera considerar las formas heterogéneas en que los sentidos analizados se despliegan y apropian en distintos contextos territoriales y en sujetos de diferentes clases, género y etnia; así como las diversas formas de resistencia y cuestionamiento que se han venido construyendo, desde distintos colectivos de trabajo y organizaciones de la sociedad civil, respecto al actual modelo empresarial del capitalismo de plataforma y a los discursos que buscan legitimarlo.

Dicha tarea parece ser particularmente importante y urgente en el contexto socio-laboral surgido de la pandemia por Covid-19, y en un escenario donde la expansión del capitalismo de plataformas y la uberización del trabajo parece expresar tendencias más transversales de reconfiguración digital de la economía capitalista a nivel global. En ese proceso, el análisis crítico de los discursos 
que buscan invisibilizar y legitimar las nuevas formas de precarización laboral de la gig economy resulta un aporte importante tanto al debate público, como a las organizaciones colectivas comprometidas con la construcción de una sociedad democrática y justa que provea un trabajo decente para todos sus integrantes.

\section{REFERENCIAS}

Antunes, Ricardo \& Filgueiras, Vitor (2020). Plataformas digitais, Uberizacao do trabalho e regulacao no Capitalismo contemporaneo. Contracampo, Niteroi, 39(1), 2743

Berg, Janine; Furrer, Marianne; Harmon, Ellie; Rani, Uma \& Silberman, M. Six (2019). Las plataformas digitales y el futuro del trabajo. https://www.ilo.org/global/publications/books/WCMS_684183/lang--es/index.html

Boltansky, Luc \& Chiapello, Eve (2002). El nuevo espíritu del capitalismo. Akal

Bröckling, Ullrich (2015). El self emprendedor. Sociología de una forma de subjetivación. Ediciones Universidad Alberto Hurtado.

CEPAL OIT (2020). Coyuntura Laboral en América Latina y el Caribe. El Trabajo en Tiempos de Pandemia: Desafíos frente a la Enfermedad por COVID-19. https: / / www.cepal.org/es/publicaciones/45557-coyuntura-laboral-america-latinacaribe-trabajo-tiempos-pandemia-desafios-frente

Czarniawska, Bárbara (2004). Narratives in Social Science Research (1st ed.). SAGE Publications Ltd.

De Stefano, Valeria (2016). The rise of the «just-in-time workforce»: On-demand work, crowdwork and labour protection in the «gig-economy». Conditions of Work and Employment Series, 71(71), 1-35.

www.ilo.org/publns\%0Ahttp://www.ilo.org/wcmsp5/groups/public/---ed_protect/--protrav/---travail/documents/publication/wcms_443267.pdf

Fleming, Peter (2017). The Human Capital Hoax: Work, Debt and Insecurity in the Era of Uberization. Organization Studies, 38(5), 691-709.

https://doi.org/10.1177/0170840616686129

Gandini, Alessandro. (2019). Labour process theory and the gig economy. Human Relations, 72(6), 1039-1056. https://doi.org/10.1177/0018726718790002

Gleim, Mark; Johnson, Catherine \& Lawson, Stephanie (2019). Sharers and sellers: A multi-group examination of gig economy workers' perceptions. Journal of Business Research, 98, 142-152. https://doi.org/10.1016/j.jbusres.2019.01.041

Goods, Caleb; Veen, Alex \& Barratt, Tom (2019). “Is your gig any good?” Analysing job quality in the Australian platform-based food-delivery sector. Journal of Industrial Relations, 0(0), 2-26. https://doi.org/10.1177/0022185618817069

Hagiu, Andrei \& Wright, Julian (2019). The status of workers and platforms in the sharing economy. Journal of Economics and Management Strategy, 28(1), 97-108.

https://doi.org/10.1111/jems.12299 
Howcroft, Debra \& Bergvall, Birgitta (2019). A Typology of Crowdwork Platforms. Work, Employment and Society, 33(1), 21-38.

https://doi.org/10.1177/0950017018760136

Ivanova, Mirela; Bronowicka, Joanna; Kocher, Eva \& Degner, Klauss (2018). The App as a boss? Control and autonomy in Application - Based Management. The British Journal of Psychiatry, 2(2), 1-27. https://doi.org/10.1192/bjp.111.479.1009-a

Kaine, Sarah \& Josserand, Emmanuel (2019). The organisation and experience of work in the gig economy. Journal of Industrial Relations, 0(0), 1-23. https://doi.org/10.1177/0022185619865480

Katz, Lawrence \& Krueger, Alan (2019). The Rise and Nature of Alternative Work Arrangements in the United States, 1995-2015. ILR Review, 72(2), 382-416. https://doi.org/10.1177/0019793918820008

Laval, Christian \& Dardot, Pierre (2013). La nueva razón del mundo. Ensayo sobre la sociedad neoliberal. Gedisa

López de la Fuente, Graciela. (2019). El trabajador joven en la economía de las plataformas: ¿Juventud, divino tesoro? The young worker in the economy of the platforms: Youth, divine treasure? International Journal of Information Systems and Software Engineering for Big Companies (IJISEBC), 6, 133-141.

MacDonald, Robert \& Giazitzoglu, Andreas (2019). Youth, enterprise and precarity: or, what is, and what is wrong with, the 'gig economy'? Journal of Sociology, 55(4), 117. https://doi.org/10.1177/1440783319837604

Madariaga, Javier; Buenadicha, César; Molina, Erika \& Ernst, Cristoph (2019). Economía de plataformas y empleo ¿Cómo es trabajar para una app en Argentina? Buenos Aires. https: //www.cippec.org/publicacion/economia-de-plataformas-y-empleocomo-es-trabajar-para-una-app-en-argentina/

Manriquez, Mariana (2019). Work-games in the gig-economy: A case study of Uber drivers in the city of Monterrey, Mexico. Research in the Sociology of Work, 33, 165188. https: / / doi.org/10.1108/S0277-283320190000033010

Melucci, Alberto (2001). Vivencia y convivencia (1era ed.). Trotta.

Muntaner, Carles (2018). Digital Platforms, Gig Economy, Precarious Employment, and the Invisible Hand of Social Class. International Journal of Health Services, 48(4), 597-600. https://doi.org/10.1177/0020731418801413

OIT (2021). Perspectivas sociales y del empleo en el mundo. El papel de las plataformas digitales en la transformación del mundo del trabajo. In Informe de referencia de la OIT. https: / /www.ilo.org/global/research/global-

reports/weso/2021/WCMS_771675/lang--es/index.htm

Pedidos Ya (2019, Junio, 14) Pide lo que quieras, que te lo llevamos volando. https: / / www.youtube.com/watch?v=WoBnt7ETmKg\&yt=1s

Portocarrero, Gonzalo (2001). Nuevos modelos de identidad en la sociedad peruana. En Gonzalo Portocarrero \& Jorge Komadina (Eds.), Modelos de identidad y sentidos de pertenencia en Perú y Bolivia (1era ed., pp. 11 - 88). IEP.

Ricouer, Paul (2003). Teoría de la interpretación. Discurso y excedente de sentido (1era ed.). Siglo XXI editores. 
Riessman, Catherine (1993). Narrative analysis. Sage

Rivera, Jerónimo \& Correa, Ernesto (2006). La imagen y su papel en la narrativa audiovisual. Razón y Palabra, 49, 107-118.

Sin Delantal (s/f) Campaña "Entrale". https://www.youtube.com/watch?v=F_E75L9aZcA

Sisto, Vicente \& Fardella, Carla (2009). Control narrativo y gubernamentalidad: La producción de coherencia en las narrativas identitarias. El caso de profesionales chilenos adultos jóvenes en condiciones de vinculación laboral flexible [70 párrafos]. Forum Qualitative Sozialforschung / Forum: Qualitative Social Research, 10(2), Art. 29, https://doi.org/10.17169/fqs-10.2.1300

Shibata, Saori (2019). Gig Work and the Discourse of Autonomy: Fictitious Freedom in Japan's Digital Economy. New Political Economy, 0(0), 1-17. https://doi.org/10.1080/13563467.2019.1613351

Smith, Rebecca \& Leberstein, Sarah (2015). Rights on Demand: Ensuring Workplace Standards and Worker Security In the On-Demand Economy. National Employment Law Project. https: //www.nelp.org/publication/rights-on-demand/

Srnicek, Nick (2018). Capitalismo de plataformas. Caja negra Editora.

Stecher, Antonio (2009). La Competencia por el éxito y la búsqueda de la autenticidad: modelos de identidad en el Chile actual. Psicoperspectivas, 8(2), 266-292 (2013).

Stecher, Antonio (2013). Un modelo crítico-interpretativo para el estudio de las identidades laborales. Contribuciones a la investigación psicosocial sobre trabajo y subjetividad en América Latina. Universitas Psychologica, 12(4), 1311-1324. https: / / doi.org/10.11144/Javeriana.UPSY12-4. mcie

Thompson, Jhon (2002). Metodología de la interpretación. Ideología y Cultura Moderna. Teoría Crítica Social En La Era de La Comunicación de Masas, 395-475. http://www.uamenlinea.uam.mx/materiales/licenciatura/diversos/THOMPSON_JOH N_B_Ideologia_y_cultura_moderna_Teoria_critica_s.pdf

Thompson, Jhon (2004). Ideología y cultura moderna. Teoría crítica social en la era de la comunicación de masas. Universidad Autónoma Metropolitana.

Uber Eats (2018, mayo 8) Uber Eats llega a Lima. https://www.youtube.com/watch?v=Qn758GRnxTA

Ugarte, José Luis (2020). Trabajo en empresas de plataforma: Subordinación y más allá. Revista Chilena de Derecho Privado, 35, 17-49.

Vaclavik, Marcia \& Pithan, Liana (2018). The agency search: The meaning of work for app drivers. Revista de Administracao Mackenzie, 19(5), 1-27. https://doi.org/10.1590/1678-6971/eRAMG180080

Vallas, Steven (2019). Platform Capitalism: What's at Stake for Workers? New Labor Forum, 28(1), 48-59. https://doi.org/10.1177/1095796018817059

Veen, Alex; Barratt, Tom \& Goods, Caleb (2019). Platform-Capital's 'App-etite' for Control: A Labour Process Analysis of Food-Delivery Work in Australia. Work, Employment and Society, 00(0), 1-19. https://doi.org/10.1177/0950017019836911 
Wayne, Lewchuk (2017). Precarious jobs: Where are they, and how do they affect well-being? Economic and Labour Relations Review, 28(3), 1-18.

https: / / doi.org/10.1177/1035304617722943

Wood, Alex; Graham, Mark; Lehdonvirta, Vili \& Hjorth, Isis (2019). Good Gig, Bad Gig: Autonomy and Algorithmic Control in the Global Gig Economy. Work, Employment and Society, 33(1), 1-20. https://doi.org/10.1177/0950017018785616

\section{MAGDALENA GARCÉS OJEDA}

Candidata a doctora en Psicología. Investigadora adjunta, Universidad Diego Portales, Santiago de Chile. magdalena.garces@mail.udp.cl https://orcid.org/0000-0003-3332-4100

\section{PAMELA FríAs CASTRO}

Candidata a doctora en Psicología. Universidad Diego Portales. Profesora, Universidad Alberto Hurtado, Chile.

pfrias@uahurtado.cl

https://orcid.org/0000-0003-3385-243X

\section{ANTONIO STECHER}

Ph. D. en Psicología Social Académico Universidad Diego Portales, Santiago de Chile.

antonio.stecher@udp.cl

https://orcid.org/0000-0001-6235-1912

\section{AGRADECIMIENTOS}

El presente artículo contó con el financiamiento de los siguientes proyectos: (1) FONDECYT Regular No 11811041 (ANID-Chile); (2) ANID-Programa Iniciativa Científica Milenio, Código NCS17_007-Núcleo “Autoridad y Asimetrías de Poder”; y (3) Beca CONICYT Doctorado Nacional 21180614.

\section{FORMATO DE CITACIÓN}

Garcés, Magdalena; Frías, Pamela \& Stecher, Antonio (2021). Sentidos del trabajo en el capitalismo de plataformas: Análisis de narrativas audiovisuales en la gig economy . Quaderns de Psicologia, 23(2), e1607. https://doi.org/10.5565/rev/qpsicologia. 1607 


\section{HISTORIA EDITORIAL}

Recibido: 20-01-2020

$1^{a}$ revisión: 25-02-2021

Aceptado: 09-07-2021

Publicado: 31-08-2021 